\title{
Advertising of Medical Devices and Principles of Claim Substantiation in European Union
}

\author{
Mariusz Malinowski* \\ Regulatory Affairs Department, HTL-Strefa S.A., Poland \\ *Corresponding author: Mariusz Malinowski, Regulatory Affairs Department, HTL-Strefa S.A., Adamowek 7, 95-035 Ozorkow, Po- \\ land. \\ To Cite This Article: Mariusz Malinowski. Advertising of Medical Devices and Principles of Claim Substantiation in European Union. Am J Bi- \\ omed Sci \& Res. 2021 - 12(4). AJBSR.MS.ID.001777. DOI: 10.34297/AJBSR.2021.12.001777.
}

Received: March 22, 2021; Published: 些 April 22, 2021

\begin{abstract}
The marketing of medical devices is extremely competitive. Successful advertising often depends on making strong and effective statements in respect to a product's performance or in comparing a product with a competitor's product. As advertising is highly regulated, especially within the medical technology industry, these statements can cause legal problems and possibly face legal sanctions. On one hand, companies are keen to challenge competitors' advertising which they believe to be inaccurate or misleading, on the other strongly defend their own marketing claims in the event of a challenge from a competitor or a regulatory body. The aim of the present review is to evaluate product promotions and advertising within the light of current regulatory frameworks and other limitations in the European Union.
\end{abstract}

Keywords: Advertisement; Promotion; Medical device; Claim; MDR

Abbreviations: EASA: European Advertising Standards Alliance; EDMA: European Diagnostics Manufacturers Association EU: European Union; AAMI; MDD: Medical Device Directive; MDR: Medical Device Regulation

\section{Introduction}

According to the Common Language Marketing Dictionary, a claim "is a statement made in advertising about the benefits, characteristics, and/or performance of a product or service designed to persuade the customer to make a purchase". For the advertising of medical devices, all mentioned statements, results and claims must be verifiable and evidenced by data, as well as properly documented.

\section{Regulatory Framework}

The rules governing the promotion and advertising of medical devices within the European Union (EU) are currently regulated by Regulation (EU) 2017/745 on medical devices (MDR) [1] and to some extent by former Council Directive 93/42/EEC regarding medical devices (MDD) [2], that each contains some basic rules relating to the promotion of medical devices. Moreover, promotion is additionally ruled by several different EU Directives of general application, by the national legislation of the EU Member States and industry codes of conduct and professional rules governing transparency and interactions between business and healthcare professionals.

\section{MDD vs MDR}

Both the MDD and the MDR require that advertising and promotion are undertaken in accordance with the intended purpose of the device $[3,4]$.

Article 2 of the MDD states, that "devices may be placed on the market and/or put into service only if they comply with the requirements laid down in this directive when duly supplied and properly installed, maintained and used in accordance with their intended purpose". Intended purpose was defined by Article 1(2) (g) as "the use for which the device is intended according to the data supplied by the manufacturer on the labelling, in the instructions and/or in promotional materials".

In the MDR 2017/745 intended purpose means, according to definitions in Article 2 "the use for which a device is intended according to the data supplied by the manufacturer on the label, in the instructions for use or in promotional or sales materials or statements and as specified by the manufacturer in the clinical evaluation". 
It is worth noting, that the intended purpose under the MDD defined as being that included by the manufacturer in promotional materials extends to sales materials in the MDR.

The requirements for claims are contained in Article 7 of the MDR, which states that: "In the labelling, instructions for use, making available, putting into service and advertising of devices, it shall be prohibited to use text, names, trademarks, pictures and figurative or other signs that may mislead the user or the patient with regard to the device's intended purpose, safety and performance by: (a) ascribing functions and properties to the device which the device does not have; (b) creating a false impression regarding treatment or diagnosis, functions or properties which the device does not have; (c) failing to inform the user or the patient of a likely risk associated with the use of the device in line with its intended purpose; (d) suggesting uses for the device other than those stated to form part of the intended purpose for which the conformity assessment was carried out". This is the categorical prohibition on the promotion of the unapproved "off-label" use of medical devices.

To confirm or disprove "the manufacturer's claims regarding the safety, performance and aspects relating to benefit-risk of devices (...)", clinical investigations should be performed on the basis of an appropriate plan of investigation reflecting the most recent scientific and technical data (MDR Annex XV, p.2.1).

At the same time, taking into account that the scope of the clinical evaluation is determined according to the "(...)nature, classification, intended purpose and risks of the device in question, as well as to the manufacturer's claims in respect of the device", any statements that appear in the labelling, instructions for use and promotional materials must be included in the current clinical evaluation report. Since the clinical evaluation of the device plays a fundamental role in the process of confirming the compliance of devices with the general safety and performance requirements, presenting statements, in the absence of any supporting evidence, omitting them in the clinical evaluation, or referring to the literature that does not provide any knowledge in this respect it is unacceptable. As a consequence, “(...)the intended use specified by the manufacturer and claims for the device defined by it (...)", will be subject to the notified body's assessment of clinical evaluations (MDR Annex VII, p. 4.5.5). This means that it will not permit medical device company marketing teams for making claims about devices unless those claims are substantiated by statistically significant clinical data.

\section{Medical Device Advertising and CE Mark}

In accordance with the provisions of Article 2 of the MDD, as a general principle, the manufacturer of a medical device may market and promote solely medical devices that are CE-marked and any kind of promotion should be restricted to the purposes for which the device has been CE-marked. As a consequence, if a device is not CE marked, it cannot be promoted within the EU. However, the MDD under specified circumstances does permit their exhibition. Article $4(3)$ of the Directive permits non-CE-marked medical devices to be displayed at trade shows and exhibitions, trade fairs, and demonstrations. However, devices used for this purpose must be accompanied by "a visible sign clearly indicating that they cannot be marketed or put into service until they have been made to comply" (validly CE-marked). The legality of advertising a medical device before CE mark has been granted, is subject to stricter restrictions in some Member States (i.e. France, Hungary) [5].

Article 17(3) of the MDD prohibits also affixing "marks or inscriptions which are likely to mislead third parties with reference to the meaning or the graphics of the CE marking". The other marks may be also "affixed to the device, to the packaging or to the instruction leaflet accompanying the device" if they do not reduce the visibility and legibility of the CE mark.

Since the Regulation contain no equivalent to Article 4(3) of the MDD this issue needs clarification from the Commission to keep permitting pre-market promotion.

\section{Other Regulations}

In addition to the requirement presented in the above sections, manufacturers must also comply with other rules laid down in EU directives governing the advertising of general products in the common market (but not directly applied to the advertising and promotion of medical devices): Directive 2005/29/EC concerning unfair business-to-consumer commercial practices [6], and Directive 2006/114/EC concerning misleading and comparative advertising [7].

Regarding comparative advertising, the provisions of Article 4 of Directive 2006/114/EC [8] are also relevant. In EU, comparative advertising is lawful when it is truthful and non-deceptive.

However, as the EU law is in the form of Directives, the requirements of the implementation into their national law, are the responsibility of the EU Member States. As a result, the manner in which the aims of the directives are achieved will vary from national legislation to national legislation.

\section{Self-Regulatory Guidance}

Self-regulatory organizations such as the European Advertising Standards Alliance (EASA) [9] set up the best practice recommendation for the procedure concerning the substantiation of claims in advertising.

Moreover, in 2015 European Diagnostics Manufacturers Association (EDMA) and of the European Medical Technology Industry (Eucomed), both members of MedTech Europe, approved the Code of Ethical Business Practice to line ethical standards for the medical technology industry across Europe [10]. The Code sets out the minimum standards to interact with healthcare professionals or healthcare organizations in reference to the sale, promotion or other activity of medical device products. 


\section{Conclusions}

In conclusion, due to the competitive nature of the medical device sector, advertising and claims substantiation are complex and challenging activities for the manufacturers. New regulations make it easier and clearer. Article 7 of the Regulations in combination with stricter requirements for clinical evaluations will provide regulators with new tools to attack unsubstantiated claims in advertising and promotion. The MDR introduces also an obligation on manufacturers to inform users of any residual risks which represent a major step forward in balancing the messages extolling only the virtues and not the risks of devices. In addition, in many countries, the role of self-regulatory bodies is becoming increasingly important.

\section{Conflict of Interest}

The author is employee of HTL-Strefa S.A.

\section{References}

1. REGULATION (EU) 2017/745 OF THE EUROPEAN PARLIAMENT AND OF THE COUNCIL of 5 April 2017 on medical devices, amending Directive 2001/83/EC, Regulation (EC) No 178/2002 and Regulation (EC) No 1223/2009 and repealing Council Directives 90/385/EEC and 93/42/ EEC.
2. COUNCIL DIRECTIVE 93/42/EEC of 14 June 1993 concerning medical devices.

3. Wright E, Roy F, Roussanov A (2010) Understanding the promotion of medical devices in the European Union. Journal of Medical Device Regulation 7(1): 3-6.

4. Dennis A (2020) Advertising medical devices in the EU - Do the MDR and IVDR represent a change in EU law? Journal of Medical Device Regulation 17(1): 21-25.

5. (2018) Connecting Europe - False advertising in life sciences. Hogan Lovells Publications.

6. DIRECTIVE 2005/29/EC OF THE EUROPEAN PARLIAMENT AND OF THE COUNCIL of 11 May 2005 concerning unfair business-to-consumer commercial practices in the internal market and amending Council Directive 84/450/EEC, Directives 97/7/EC, 98/27/EC and 2002/65/EC of the European Parliament and of the Council and Regulation (EC) No 2006/2004 of the European Parliament and of the Council ('Unfair Commercial Practices Directive').

7. DIRECTIVE 2006/114/EC OF THE EUROPEAN PARLIAMENT AND OF THE COUNCIL of 12 December 2006 concerning misleading and comparative advertising.

8. Directive 2006/114/EC of the European Parliament and of the Council of 12 December 2006 concerning misleading and comparative advertising.

9. (2012) EASA Best Practice on Claims Substantiation. European Advertising Standards Alliance (EASA), Belgium.

10. (2015) The MedTech Europe Code of Ethical Business Practice. MedTech Europe, Belgium. 